Гусарова И. А. ${ }^{1}$, Потапов А. М. ${ }^{1}$, Манько Т. А. ${ }^{2}$, Фальченко Ю. В. ${ }^{3}$, Петрушинец, Л. В. ${ }^{3}$, Фролов Г. А. ${ }^{4}$, Солнцев В. П. ${ }^{4}$

${ }^{1}$ Государственное предприятие «Конструкторское бюро «Южное» им. М. К. Янгеля», Украина, г. Днепр

2 Днепровский национальный университет имени Олеся Гончара. Украина, г. Днепр

${ }^{3}$ Институт электросварки им. Е. О. Патона НАН Украины. Украина, г. Киев

${ }^{4}$ Институт проблем материаловедения им. Н. Е. Францевича НАН Украины. Украина, г. Киев

\title{
ПРОБЛЕМЫ СОЗДАНИЯ ТЕПЛОЗАЩИТЫ ВОЗВРАЩАЕМЫХ АЭРОКОСМИЧЕСКИХ АППАРАТОВ
}

\begin{abstract}
Одной из основных проблем создания многоразовых аэрокосмических летательных аппаратов является разработка материалов жаростойких и теплозащитных конструкций. Украинскими специалистами создана теплозащитная конструкция с наружной металлической панелью из нового сплава ЮИПМ-Ni20Cr6Al на основе нихрома с алюминием, получаемого по порошковой технологии. Сплав обладает достаточным уровнем прочностных свойств при экстремально высоких температурах, однако его относительное удлинение не превышает 10-12\%, ито вызывает определенные проблемы при его технологических переделах. Разработана технология прокатки сплава ЮИПМ-Ni20Cr6Al до требуемых толщин и диффузионной сварки трехслойной панели. Показано, ито основным ограничивающим фактором создания таких конструкций является отсутствие оборудования для прокатки заготовок и их сварки. [dx.doi.org/10.29010/081.6]
\end{abstract}

Ключевые слова: жаростойкие материалы, теплозащитных конструкиии, диффузионная сварка, прокатка, технология.

Над созданием многоразовых аэрокосмических летательных аппаратов ученые и инженеры ведущих космических держав мира работают уже более полувека. Полеты орбитальных космических самолетов «Спейс Шаттл» (США) и «Буран» (СССР) убедительно доказали техническую возможность их создания, но вместе с тем продемонстрировали и недостатки, к которым относится высокая стоимость изготовления и эксплуатации, а также недостаточная надежность [1]. Несмотря на то, что эти программы были закрыты, работы по созданию возвращаемых транспортно-космических систем продолжаются, поскольку существенно снизить стоимость выведения объектов на орбиту позволит только многократное их использование.

Многоразовая транспортно-космическая система (МТКС) - это космический корабль, конструкция которого предусматривает многократное использование всего корабля или его основных частей после возвращения из полета. В настоящее время наиболее перспективными являются двухступенчатые транспортно-космические системы, состоящие из самолета-разгонщика и орбитального космического самолета (ОКС).

Одна из основных проблем создания как самолета-разгонщика, являющегося крылатой первой ступенью, так и орбитального космического самолета, состоит в разработке материалов жаростойких и теплозащитных конструкций, требования к которым существенно отличаются от таковых для одноразовых изделий ракетно-космической техники, поскольку здесь аблирующая тепловая защита практически не используется.

Требования к теплозащитным и жаростойким материалам аэрокосмических летательных аппаратов транспортно-космических систем определены на основании анализа требований к соответствующим конструкциям [2]. Несмотря на то, что на орбитальном космическом самолете максимальные тепловые потоки реализуются при спуске в атмосфере, а на самолете-разгонщике на участке выведения, температуры функционирования жаростойких конструкций МТКС и теплозащитных конструкций ОКС идентичны, и основные требования к материалам этих конструкций также одинаковы. Максимальные рабочие температуры составляют $1150-1100{ }^{\circ} \mathrm{C}$, количество термоциклов 100-500, общее время работы материалов при максимальных температурах - 1700-2000 минут. Наиболее сложной задачей является разработка теплозащиты наветренной части орбитального космического самолета, так здесь температуры

(C) Гусарова И. А., Потапов А. М., Манько Т. А., Фальченко Ю. В., Петрушинец Л. В., 
порядка $1100{ }^{\circ} \mathrm{C}$ реализуются на площади, которая составляет 40-45 \% от всей поверхности корабля.

Украинскими специалистами разработана теплозащитная конструкция с металлической наружной панелью для многоразовых аэрокосмических аппаратов. Целью данной работы является определение основных проблемных вопросов выбора материалов и технологий для изготовления данной теплозащиты.

При выборе жаростойких материалов теплозащитных конструкций основными критериями являются удельные прочностные свойства, которые должны сохраняться при большом количестве термоциклов в рабочем диапазоне температур. При существующем уровне производства предпочтение следует отдать новым сплавам с повышенными механическими характеристиками, поскольку металлы являются самыми надежными конструкционными материалами, их преимущества обусловлены наличием металлической связи, что придает им способность к пластической деформации и самоупрочнению, а также позволяет вести обработку давлением и изготавливать сложнопрофильные и тонкостенные конструкции.

Выбор материалов проводился с учетом максимальных напряжений в силовых элементах теплозащитной конструкции, полученных на основе анализа ее напряженно-деформированного состояния (рис. 1), выполненного методом конечных элементов с использованием пакета программ MSC. Nastran.

Геометрические параметры макета теплозащитной конструкции (рис. 2):

- размер плитки $144 \times 144$ мм², $^{2}$

- толщины наружной обшивки 0,4 мм,

- толщины внутренней обшивки 0,15 мм,

- высота трехслойной панели 12 мм,

- размер грани сотового заполнителя 15 мм,

- толщина стенки опоры 0,1 мм,

- толщина стенок сотового заполнителя и боковых ограничителей 0,1 мм.

Максимальные механические и тепловые нагрузки, действующие на теплозащиту при старте и возвращении многоразового космического аппарата, включают нагружение аэродинамическим давлением на нижнем атмосферном участке спуска и посадке - 0,05 МПа, и нагружение давлением 0,01 МПа при возвращении при температуре наружной поверхности $1100{ }^{\circ} \mathrm{C}$ и $200{ }^{\circ} \mathrm{C}$ в точке контакта с силовой оболочкой космического аппарата. Наружное давление, действующее на исследуемые конструкции, рассчитывается с учетом коэффициента безопасности на давление $f=1,3$, его максимальные значения составляют соответственно 0,065 МПа и 0,013 МПа.

Оптимальным вариантом расчета является нагружение давлением 0,013 МПа при температуре наружной поверхности $1100{ }^{\circ} \mathrm{C}$, поскольку при этом реализуются максимальные тепловые расширения панелей плитки и, соответственно, в конструкционных элементах возникают максимальные напряжения. Результаты прочностного анализа (таблица 1), показали, что максимальные напряжения в различных элементах конструкции при температуре $20^{\circ} \mathrm{C}$ составляют $196 \mathrm{MПа,} \mathrm{при} \mathrm{темпе-}$ ратуре $900{ }^{\circ} \mathrm{C}-464$ МПа, а при температуре $1100{ }^{\circ} \mathrm{C}-44$ МПа.

Наиболее распространенными жаростойкими сплавами, используемыми в конструкциях многоразовых аэрокосмических аппаратов, работающих при повышенных температурах, являются дисперсионно стареющие сплавы на основе нихрома нимоники. Теплозащитные конструкции КА Х-33, ARMOR, NASA Langley Research Center, а также наружная панель компании Dutch Space, изготовлены из сплава данного класса - Inconel 617. Однако его предел прочности при температуре $900{ }^{\circ} \mathrm{C}$ составляет $120 \mathrm{MПа,} \mathrm{прочность} \mathrm{известных}$ жаростойких нимоников при данной температуре не превышает 230 МПа, их рабочие температуры ограничены $900{ }^{\circ} \mathrm{C}$, удельный вес -8300 кг $/ \mathrm{m}^{3}$.

При термоциклировании в диапазоне температур 20-1100 ${ }^{\circ} \mathrm{C}$ в окислительной среде, что характерно для участка спуска в атмосфере многоразовых аэрокосмических аппаратов, способны рабо-

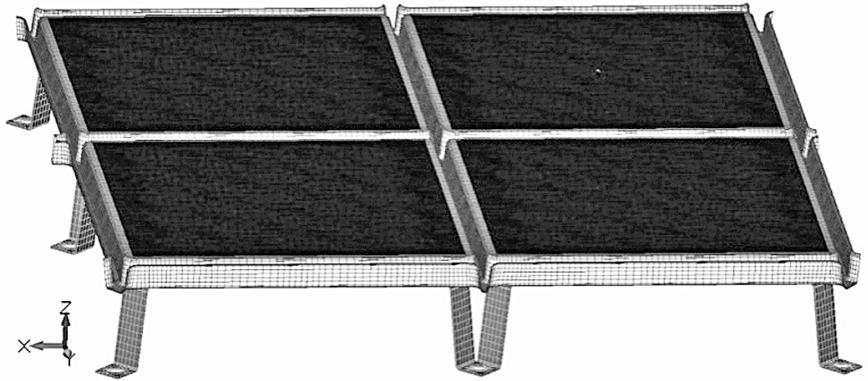

Рис. 1. Модель теплозащитной конструкции

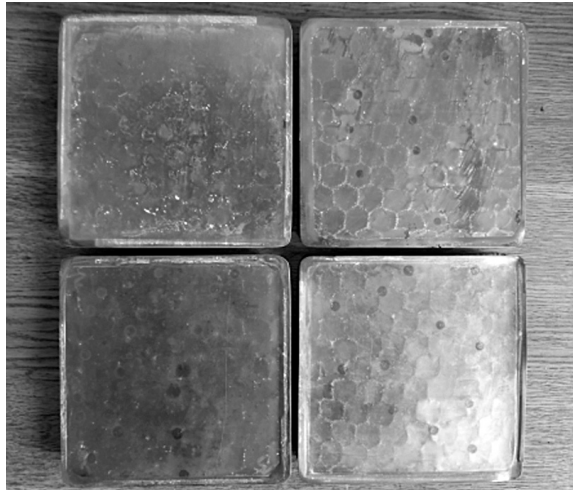

Рис. 2. Макет теплозащитной конструкции 
Результаты оценки прочности силовых элементов плитки

\begin{tabular}{|c|c|c|c|}
\hline Силовой элемент & Расчетный случай & $\begin{array}{c}\text { Teмпература, } \\
{ }^{\circ} \mathbf{C} \\
\end{array}$ & $\begin{array}{c}\text { Максимальное напряжения, } \\
\text { МПа } \\
\end{array}$ \\
\hline \multirow{3}{*}{ Пластина верхняя } & Давление & 20 & 46,9 \\
\hline & Температура & 1100 & 7,6 \\
\hline & Температура+давление & 1100 & 7,5 \\
\hline \multirow{3}{*}{ Соты } & Давление & 20 & 167,4 \\
\hline & Температура & 1100 & 43,8 \\
\hline & Температура+давление & 1100 & 32,3 \\
\hline \multirow{3}{*}{ Пластина нижняя } & Давление & 20 & 116,7 \\
\hline & Температура & 1100 & 41,7 \\
\hline & Температура+давление & 1100 & 44,0 \\
\hline \multirow{3}{*}{ Пластины боковые } & Давление & 20 & 196,4 \\
\hline & Температура & 1100 & 38,5 \\
\hline & Температура+давление & 1100 & 22,5 \\
\hline \multirow{5}{*}{ Опоры } & Давление & 20 & 173,2 \\
\hline & \multirow[t]{2}{*}{ Температура } & 900 & 463,9 \\
\hline & & 150 & 725,7 \\
\hline & \multirow[t]{2}{*}{ Температура+давление } & 900 & 452,6 \\
\hline & & 150 & 655,5 \\
\hline
\end{tabular}

тать дисперсно-упрочненные порошковые сплавы с оксидом иттрия $\left(\mathrm{Y}_{2} \mathrm{O}_{3}\right)$, поскольку он упрочняет сплав при высоких температурах и способствует образованию прочной защитной пленки на поверхности. Такой сплав ЮИПM-Ni20Cr6Al, получаемый по порошковой технологии и имеющий пониженный удельный вес - 7500 кг м $^{3}$, разработан специалистами Института проблем материаловедения НАН Украины (ИПМ НАНУ) и ГП «КБ «Южное». Зависимость прочности сплава при растяжении от температуры приведена на рис. 3.

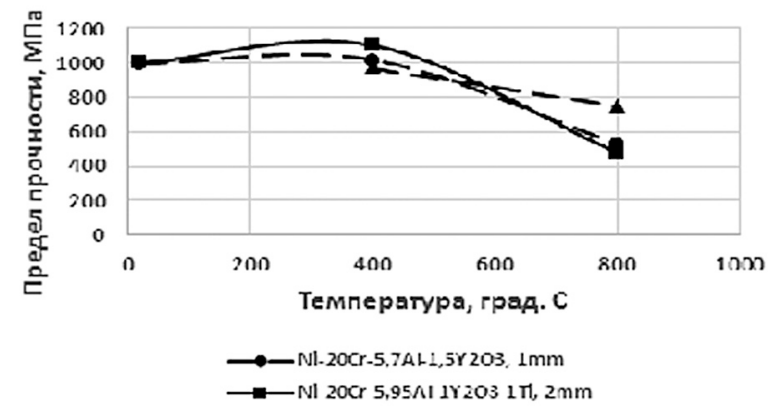

Близкие значения прочности в вакууме и на воздухе свидетельствуют о высокой стойкости к окислению материала, при этом прочность сплава при температурах до $1100{ }^{\circ} \mathrm{C}$ превышает напряжения, возникающие в теплозащитной конструкции (таблица 1). Запас прочности, определяемый как отношение предела прочности при данной температуре к максимальным напряжениям, возникающем в каждом силовом элементе, составляет не менее 1,35. По результатам прочностных расчетов сплав ЮИПМ-Ni20Cr6Al пригоден для жаростойких сило-

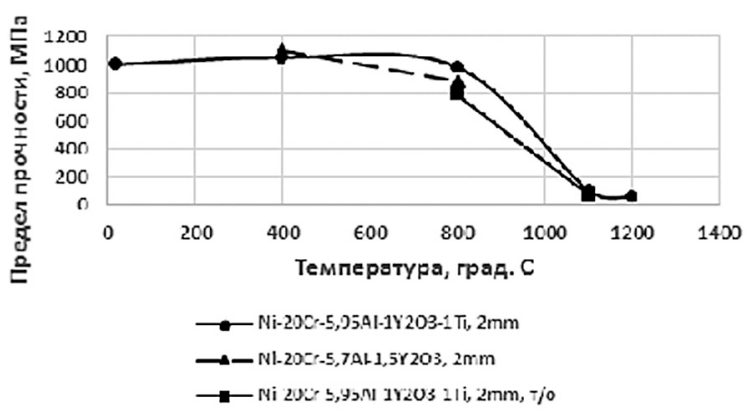

Рис. 3. Прочность сплава при растяжении: а - на воздухе, б - в вакууме 


\section{Tixponorinuceckn:TC 4/2017}

вых элементов теплозащитной конструкции многоразовых аэрокосмических аппаратов и может быть использован для изготовления макета конструкции.

Однако те свойства сплава, которые определяют его работоспособность при повышенных температурах, вызывают определенные проблемы при его технологических переделах, первым из которых является прокат заготовок до листов различной толщины.

Сплав ЮИПM-Ni20Cr6Al, полученный по порошковой технологии, имеет повышенную пористость, и его нельзя нагревать в атмосфере воздуха, поскольку при температуре свыше $1000{ }^{\circ} \mathrm{C}$ при наличие открытой пористости происходит насыщение структуры кислородом, что приводит к охрупчиванию заготовок. Вследствие этого на начальном этапе, при прокатке заготовки от 24 до 3,5 мм была использована холодная прокатка на прокатном стане «DUO 500» (ИПМ НАНУ) со степенью обжатия 2-3\% за проход с промежуточными отжигами в вакууме.

При толщине листа 3,5 мм сплав имеет только закрытую пористость, поэтому дальше ведется горячая прокатка с промежуточными отжигами на воздухе до толщин 0,4 мм. Для получения фольг толщиной менее 0,1 мм использована холодная прокатка, что обусловлено окислением поверхности сплава при высоких температурах.

Металлографические исследования фольги сплава ЮИПM-Ni20Cr6Al, проведенные на образцах в виде полос шириной 10..15 мм, ориентированных вдоль проката, показали, что после термической обработки и проката при получении фольги, на ее поверхности формируется плотная оксидная пленка толщиной 1,5...2 мкм (рис. 4).

В сплаве наблюдаются отдельные светлые включения диоксида иттрия. Микротвердость данного участка фольги составляет 6,7 ГПа, возможно в результате образования на поверхности сплава шпинели сложного химического состава. Микротвердость нижележащих участков фольги и в ее центре составляет соответственно 4,6 и 3,7 ГПа.

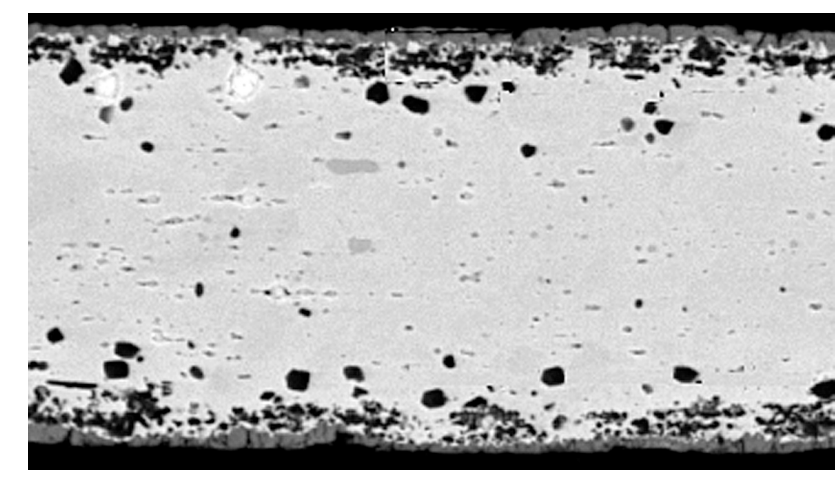

Рис. 4. Микроструктура фольги сплава ЮИПМ-Ni20Cr6Al в состоянии поставки

Состояние наклепанного металла, имеющего избыточную энергию, термодинамически неустойчиво. При нагреве такого металла в нем протекают процессы возврата и рекристаллизации, приводящие к возвращению всех свойств металла к свойствам до деформации. Поэтому после каждого цикла прокатки проводят отжиг при температуре $1200{ }^{\circ} \mathrm{C}$, что определяется высокой температурой рекристал-лизации сплава, составляющей 0,9Tпл.

Влияние прокатки на микроструктуру показано на рис. 5. После холодной прокатки на толщину 5 мм пористость практически не изменяется по сравнению со спеченной заготовкой (рис. 5, а). Прокатка на 2 мм (рис. 5, б) и тем более на 1 мм (рис. 5, в) приводит к сплющиванию и частичному залечиванию пор [3]. После прокатки на 1 мм сплющенные поры во многих местах представляются на шлифе в виде цепочек или отдельных мелких пор. Выявление границ зерен при травлении показывает, что после прокатки зерна деформируются, сплющиваются, и вытягиваются вдоль проката. Такой характер пластического течения приводит к изменению внутризеренной структуры - дроблению блоков мозаики и уменьшению размера зерна. Средний размер зерна уменьшается от 25 мкм при толщине листа 2 мм (рис. 5, б) до 20 мкм при толщине образца 1 мм (рис. 5, в). Размер зерен не однородный, есть много зерен с размером 10 мкм и меньше.

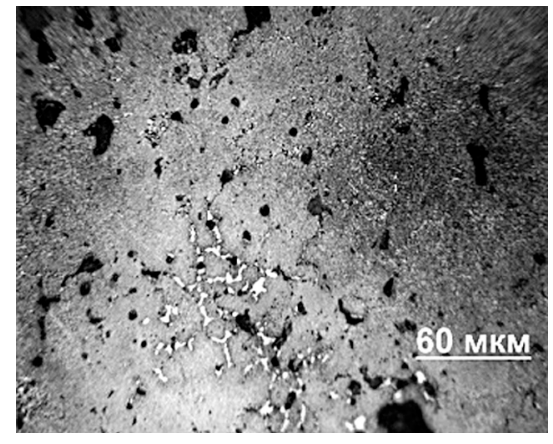

a

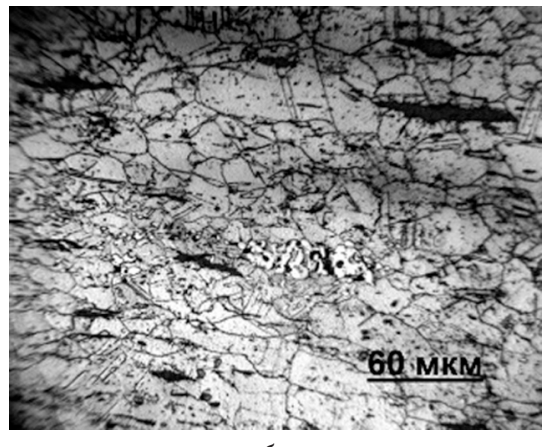

б

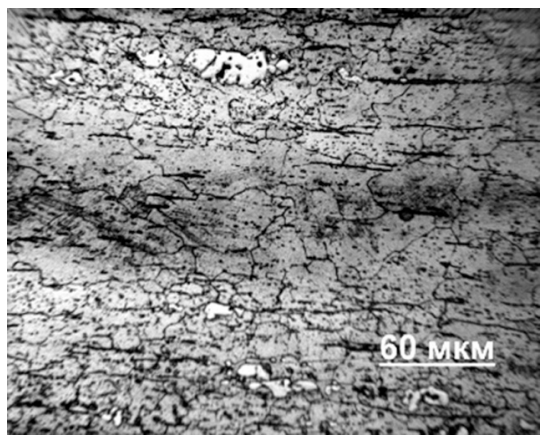

Рис. 5. Микроструктура сплаваЮИПМ-Ni20Cr6Al:

a - нетравленый сплав, толщина 5 мм, б - травленый сплав, толщина 2 мм, в - травленый сплав, толщина 1 мм. х900 


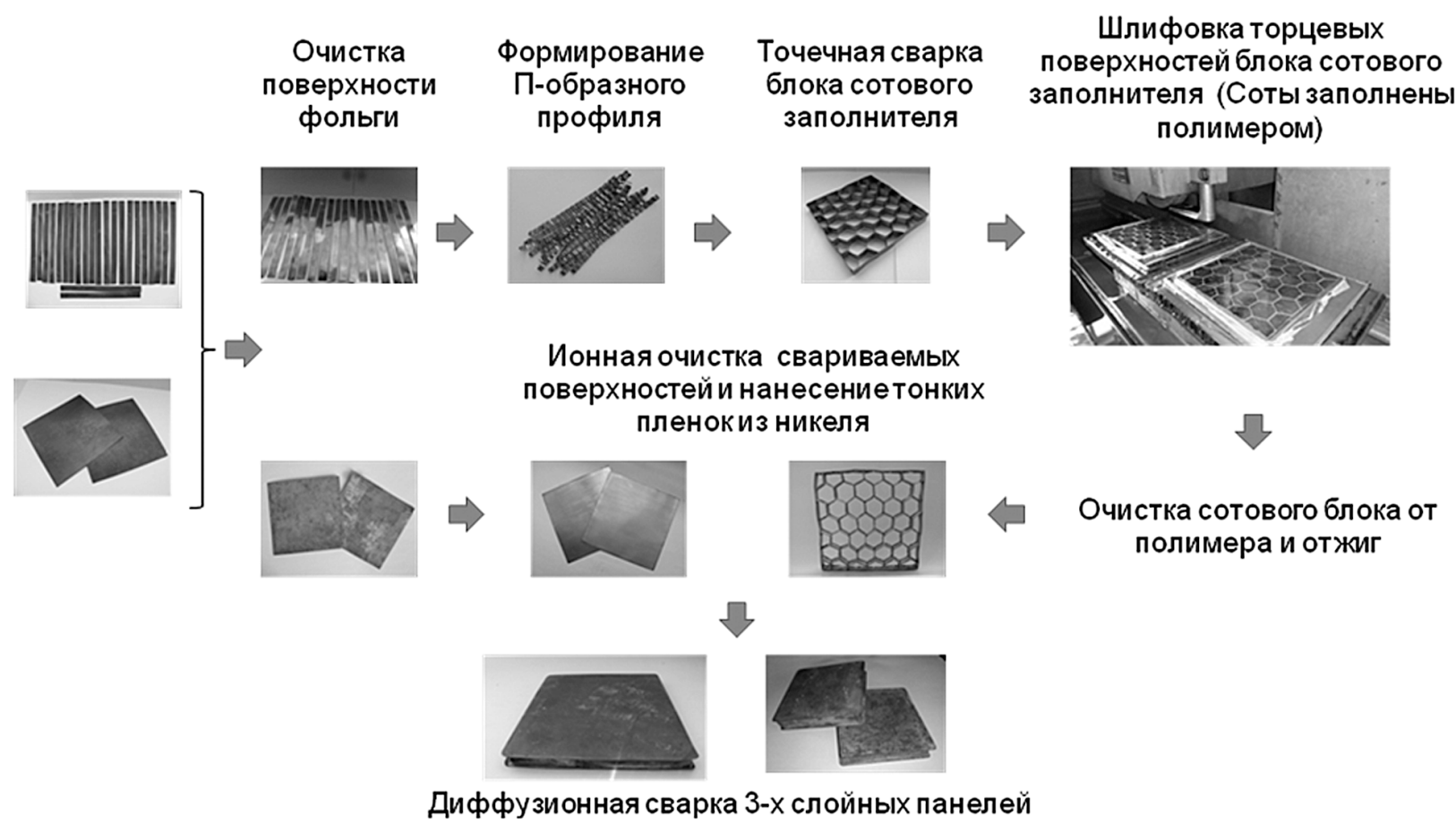

Рис. 6. Схема основных технологических операций по производству трехслойных сотовых панелей

Основные технологические операции по сборке трехслойных сотовых панелей с помощью сварки приведены на рис. 6.

Сотовый заполнитель формировали из профилированной ленты фольги точечной сваркой, что позволяло ускорить процесс сборки блока сотового заполнителя.

Существующие технологии сборки сотового заполнителя с обшивками можно разбить на сварку плавлением, пайку и сварку давлением. Для сохранения преимуществ порошкового сплава сварка должна проводиться в твердой фазе, что исключает применение сварки плавлением лазерной и электронно-лучевой. Наиболее перспективным методом интеграции элементов трехслойной конструкции в панель является сварка давлением - диффузионная сварка [4], которую можно вести с применением или без промежуточных прослоек.

Диффузионную сварку трехслойной панели из сплава ЮИПМ-Ni20Cr6Al, проводили на установке П 115, а сварку образцов из сплава нихрома на установке У-394, что обусловлено размерами их рабочих камер и производительностью. Сложность получения соединений из жаропрочных сплавов на основе никеля методом диффузионной сварки заключается в образовании на их поверхности термически стойкого слоя оксида и низкой пластичности данной группы материалов. Как правило, при сварке без промежуточных прослоек с учетом нахождения на поверхности жаропрочных никеле- вых сплавов термически устойчивой оксидной пленки, необходимо применять жесткие режимы сварки. Однако, такой технологический прием при сварке сотовых конструкций приводит к деформации сотового заполнителя. Для облегчения условий удаления оксидной пленки со свариваемых поверхностей и локализации пластической деформации в стыке применяется диффузионная сварка через промежуточные прослойки. Протекание в прослойке твердофазных реакций в процессе ее нагрева способствует формированию соединения при более мягких условиях, чем традиционные способы сварки [5].

В качестве промежуточных прослоек для сварки применялась фольга из пористого никеля с пористостью $23 \%$ об. и многослойная фольга системы $\mathrm{Cu}-31,68$ \% вес. Ті с периодом чередования слоев 0,86 мкм. Обе фольги были получены по технологии электроннолучевого испарения и конденсации в вакууме в ИЭС им. Е.О. Патона. Толщина фольги составляла соответственно 25 и 40 мкм.

Для устранения пластической деформации оснастки в процессе нагрева сварку образцов из фольги сплава ЮИПМ-Ni20Cr6Al проводили с применением пуансона и матрицы, изготовленных из интерметалидного сплава $\boldsymbol{\gamma}$-TiAl. Данный сплав отличается повышенной жаростойкостью и низкими значениями пластичности при температурах сварки.

Технологический цикл сварки состоял в нагреве образцов до температуры сварки, приложении 

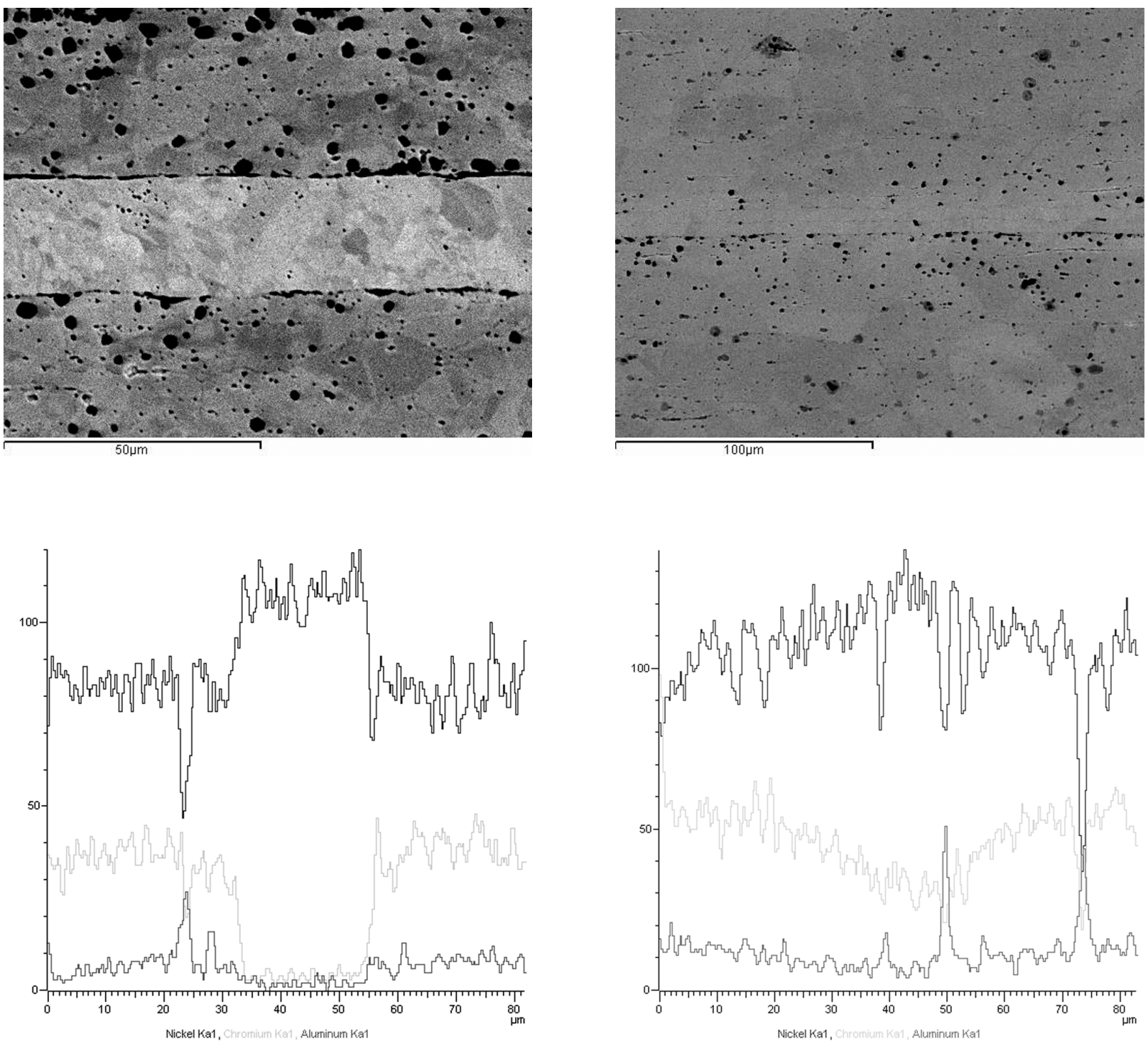

б

Рис. 7. Микроструктура и распределение химических элементов в зоне соединения образцов из сплава ЮИПМ-Ni20Cr6Al с прослойкой из пористого никеля: а - температура сварки $800{ }^{\circ} \mathrm{C}, 6$ - температура сварки $1200{ }^{\circ} \mathrm{C}$

нагрузки, выдержке под нагрузкой в течении 20 минут, снятии нагрузки и охлаждении до температуры 40-50 ${ }^{\circ} \mathrm{C}$. Удельное давление сварки в обоих случаях составляло 40 МПа. На рисунках 7 а, б представлена микроструктура сварных соединений из сплава ЮИПM-Ni20Cr6Al, полученных с применением прослойки из пористого никеля при температуре сварки 800 и $1200{ }^{\circ} \mathrm{C}$.

При увеличении температуры сварки с 800 до $1200{ }^{\circ} \mathrm{C}$ в сварных соединениях наблюдается снижение дефектности структуры (рис. 7 а, б). Необходимо отметить, что как при температуре сварки $800{ }^{\circ} \mathrm{C}$, так и при температуре сварки $1200{ }^{\circ} \mathrm{C}$, в стыке наблюдается сходный характер распределения химических элементов.
Сварку сплава ЮИПМ-Ni20Cr6Al с применением промежуточной прослойки системы $\mathrm{Cu} / \mathrm{Ti}$ проводили при температуре $900{ }^{\circ} \mathrm{C}$ и $1200{ }^{\circ} \mathrm{C}$, давлении 40 МПа, продолжительности сварки 20 минут. Микроструктура сварных соединений представлена на рис. 8 а, б. При температуре сварки $900{ }^{\circ} \mathrm{C}$ в зоне соединения происходит формирование физического контакта и развитие диффузионных процессов, о чем может свидетельствовать образование со стороны сплава нихрома на удалении 0,5...1 мкм от линии соединения оторочки серого цвета (рис. 8, a). В зоне соединения наблюдается остаточная слоистость, обусловленная не полным протеканием химического взаимодействия между отдельными слоями в прослойке. 


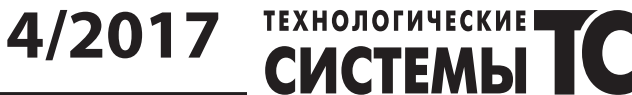

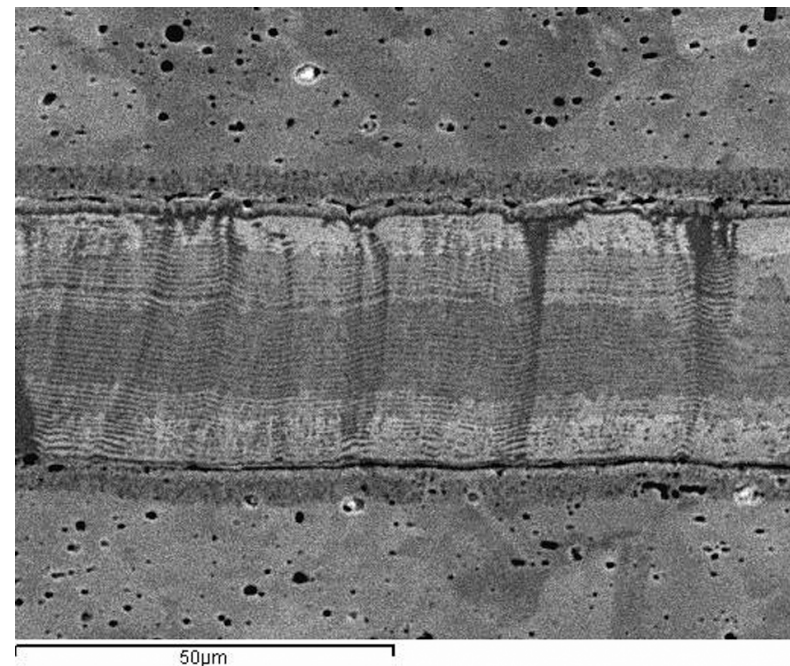

a

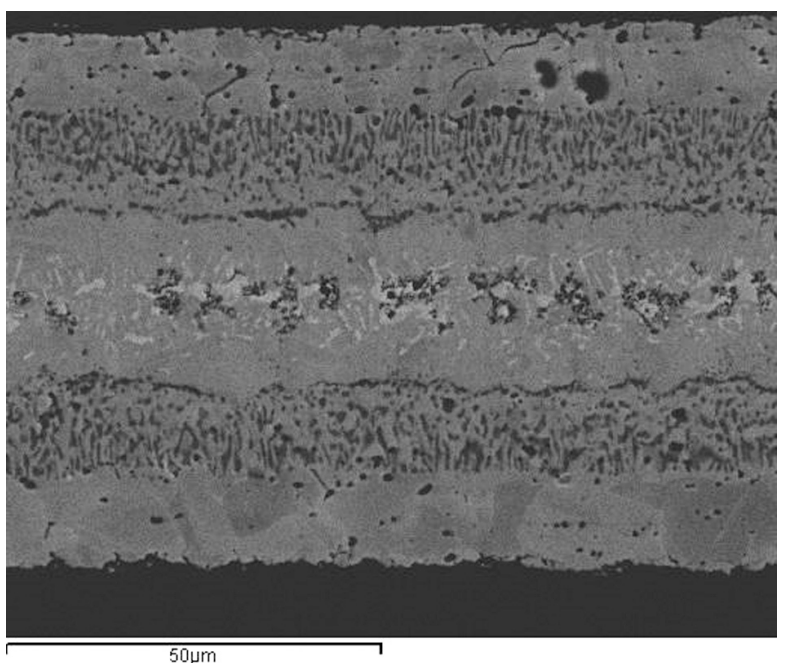

б

Рис. 8. Микроструктура соединений из сплава ЮИПМ-Ni20Cr6Al, полученных с применением прослойки системы $\mathrm{Ti} / \mathrm{Cu}$ :

a - температура сварки $900{ }^{\circ} \mathrm{C}, \sigma$ - температура сварки $1200{ }^{\circ} \mathrm{C}$

Увеличение температуры сварки до $1200{ }^{\circ} \mathrm{C}$ обуславливает ускорение протекания диффузионных процессов в стыке, о чем свидетельствует исчезновение слоистости и формирование более широкой зоны соединения (рис. 8, б).

Механические свойства сплава ЮИПМ$\mathrm{Ni} 20 \mathrm{Cr} 6 \mathrm{Al}$ и сварных соединений, полученных при диффузионной сварке в вакууме с применением прослоек на основе пористого $\mathrm{Ni}$ и многослойной фольги системы $\mathrm{Cu} / \mathrm{Ti}$, исследовали на растяжение на плоских образцах толщиной 0,1 мм. Для испытания применяли машину MTS-810. Результаты механических испытаний сварных соединений на растяжение приведены в табл. 2.

Таблица 2

Результаты механических испытаний сплава ЮИПМ-Ni20Cr6Al и сварных соединений

\begin{tabular}{|c|c|c|c|c|c|c|}
\hline \multirow{2}{*}{$\begin{array}{l}\text { № } \\
\text { ПI/ா }\end{array}$} & \multirow[b]{2}{*}{ Тип образца } & \multirow{2}{*}{$\begin{array}{c}\text { Прослойка } \\
\text { толщина, } \\
\text { мм } \\
\end{array}$} & \multicolumn{2}{|c|}{ Место разрушения образцов } & \multirow{2}{*}{$\begin{array}{l}\sigma_{\mathrm{s}}, \\
\text { МПа }\end{array}$} & \multirow{2}{*}{$\begin{array}{l}\sigma_{\text {вср }}, \\
\text { МПа }\end{array}$} \\
\hline & & & $\begin{array}{c}\text { Основной } \\
\text { металл }\end{array}$ & $\begin{array}{c}\text { Зона } \\
\text { соединения }\end{array}$ & & \\
\hline 1 & \multirow{3}{*}{ ЮИПМ-Ni20Cr6Al } & \multirow{3}{*}{-} & + & - & 272 & \multirow{3}{*}{309,7} \\
\hline 2 & & & + & - & 297 & \\
\hline 3 & & & + & - & 360 & \\
\hline 1 & \multirow{3}{*}{ Сварное соединение } & \multirow{3}{*}{$\begin{array}{l}\mathrm{Cu} / \mathrm{Ti} \\
\delta=0,04\end{array}$} & + & - & 27,9 & \multirow{3}{*}{220,7} \\
\hline 2 & & & + & - & 272,4 & \\
\hline 3 & & & + & - & 361,9 & \\
\hline 1 & \multirow{3}{*}{ Сварное соединение } & \multirow{3}{*}{$\begin{array}{c}\mathrm{Ni} \\
\delta=0,03\end{array}$} & + & - & 187,5 & \multirow{3}{*}{264,3} \\
\hline 2 & & & + & - & 200,0 & \\
\hline 3 & & & + & - & 405,4 & \\
\hline
\end{tabular}




\section{TrxonorinuteckntTC 4/2017}

Как видно из результатов механических испытаний предел прочности при растяжении на образцах фольги толщиной 0,1 мм составляет 309,7 МПа, что в 3 раза ниже, чем значения, полученные на образцах толщиной 1-2 мм (рис. 1). Этот факт свидетельствует о влиянии толщины (начиная с определенных значений) на прочностные свойства сплава. Результаты испытаний подтверждаются литературными данными. Так в соответствии с уменьшением диаметра проволоки из сплавов нихрома наблюдается снижение их срока службы [6]. Для сплава Х20Н80-Н при диаметре проволоки 6 мм и более при температуре испытаний $1200{ }^{\circ} \mathrm{C}$ срок службы проволоки составляет не менее 4000 часов, а для проволоки диаметром менее 0,4 мм при рабочей температуре $950{ }^{\circ} \mathrm{C}$ срок службы составляет уже не менее 800 часов. Полученные данные свидетельствуют о том, что необходимо учитывать зависимость прочностных свойств тонкостенных силовых элементов трехслойных конструкций от их толщины.

В сварных соединениях, полученных с применением промежуточных прослоек на основе пористого $\mathrm{Ni}$ и многослойных системы $\mathrm{Cu}-\mathrm{Ti}$, разрушение образцов наблюдается за зоной соединения. В случае применения многослойной фольги $\mathrm{Cu} / \mathrm{Ti}$ средняя прочность соединений составляет $220,7 \mathrm{MПа}$ (71\% от прочности основного металла), а в случае применения фольги из пористого Ni средняя прочность соединений составляет 264,3 МПа (85 \% от прочности основного металла). Снижение прочностных свойств на границе фольга $\mathrm{Cu} / \mathrm{Ti}$ - сплав ЮИПМ-Ni20Cr6Al может быть связано с развитием диффузионных процессов в стыке (рис. 8, а) и взаимной диффузией элементов прослойки и сплава. Снижение прочностных свойств вдоль границы фольга пористого никеля - сплав ЮИПМNi20Cr6Al может быть обусловлено скоплением пор (рис. 7). В соответствии с данными работы [3], в процессе термо-механического воздействия в порошковых материалах (фольге) под воздействием температуры и давления происходят процессы роста и залечивания пор, что может быть причиной расположения пор вдоль границы с прослойкой.

При изготовлении макета наружной панели теплозащитной конструкции многоразовых аэрокосмических аппаратов прокатка и сборка велась на лабораторном оборудовании, поэтому размеры макета ограничены возможностями существующего оборудования [7,8]. Одной из основных проблем при создании таких конструкций является отсутствие как в Украине, так и в Европе, оборудования для изготовления полномасштабных штатных образцов. Создание такого оборудования требует значительных затрат, что является сдерживающем фактором при создании теплозащитных конструкций.

\section{Выводы}

В Украине создана теплозащитная конструкция с наружной металлической панелью для многоразовых аэрокосмических аппаратов, и сплав ЮИПМ-Ni20Cr6Al на основе нихрома с алюминием с требуемым уровнем свойств, получаемый по порошковой технологии для изготовления силовых элементов данной конструкции.

Показано, что для сборки трехслойной панели из данного сплава может использоваться диффузионная сварка и выбраны ее оптимальные режимы.

Показано, что основным ограничивающим фактором создания таких конструкций является отсутствие дорогостоящего оборудования для прокатки и сварки штатных образцов теплозащиты.

\section{Литература}

[1] Гофин М.Я. Жаростойкие и теплозащитные конструкции многоразовых аэрокосмических аппаратов. - Москва. - 2003, 658 с.

[2] Гусарова И.А., Манько Т.А., Потапов А.М. Теплозащитные конструкции аэрокосмических самолетов. Днепр. - 2017, 148 с.

[3] Скороход В.В., Уварова I.В., Рагуля А.В. Фізикохімічна кінетика в наноструктурных системах. Київ: Академперіодика. - 2001, 179 с.

[4] Казаков Н.Ф. Диффузионная сварка материалов. М.: Машиностроение. - 1976, 312 с.

[5] Устинов А.И., Матвиенко А.Я, Полищук С.С., Шишкин А.Е. Исследование фазовых превращений и пластической деформации при непрерывном нагреве многослойной фольги $\mathrm{Al} / \mathrm{Cu}$. Автоматическая сварка. - 2009. - №10. - С. 29 - 34.

[6] ГОСТ 12766.1-90. Межгосударственный стандарт. Проволока из прецизионных сплавов с высоким электрическим сопротивлением. Технические условия. М., ИПК Издательство стандартов, 2003.

[7] Фальченко Ю.В., Устинов А.И., Петрушинец Л.В., Мельниченко Т.В., Федорчук В.Е., Яценко В.А. Патент на полезную модель, № 113424 Украина, МПК В23К 20/14. Устройство для диффузионной сварки трехслойных сотовых панелей. 2017.

[8] Фальченко Ю.В., Петрушинец Л.В., Гусарова И.А., Потапов О.И. Заявка на патент №201701746 23.02.2017 - Конструкция объемного сотового заполнителя и метод изготовления сотовой панели. 
Husarova I. O. ${ }^{1}$, Potapov O. M. ${ }^{1}$, Manko T. A. ${ }^{2}$, Falchenko Y. V. ${ }^{3}$, Petrushintsev L..$^{3}$, Frolov G. A. ${ }^{4}$, Soltsev V.P. ${ }^{4}$

${ }^{1}$ Yuzhnoye, State-owned Design Office named after M. K. Yangel. Ukraine, Dnipro

${ }^{2}$ Dnipro National University named after Oles Honchar. Ukraine, Dnipro

${ }^{3}$ E. O. Paton Electric Welding Institute of National Academy of Sciences of Ukraine. Ukraine, Kiev

${ }^{4}$ Frantsevich Institute for Problems of Materials Science of National Academy of Sciences of Ukraine.

Ukraine, Kiev

\section{PROBLEMS OF CREATIONS OF REUSABLE SPACECRAFT HEAT PROTECTION}

One of the main problems of reusable spacecraft creation is development of materials for heat-proof and heat-protection structures. Ukrainian specialists has created heat-protection structure with outer metallic panel made of nеш ЮИПМ-Ni20Cr6Al alloy on the basis of nichrome and aluminum, obtained using pozeder technology. Alloy has sufficient level of mechanical strength characteristics in conditions of extremely high temperatures, but its percent elongation does not exceed 10-12\% that cause specific problems during alloy technological treatment. Rolling technology of ЮИПМ-Ni20Cr6Al alloy to required thickness is developed as well as technology for diffusion wielding of three-layer panel. It was demonstrated that the main limiting factor for this type of structure creation is an absence of equipment for blanks rolling and wielding. [dx.doi.org/10.29010/081.6]

Keywords: heat-proof materials; heat-protection structures; diffusion wielding; rolling; technology.

\section{References}

[1] Gophin M.Y. Heat-proof and heat-protection structures of reusable spacecraft. - Moskow. - 2003, 658 p.

[2] Husarova I.O., Manko T.A., Potapov O.M. Heat-protection structures of aerospace planes. - Dnipro. - 2017, 148 p.

[3] Skorohod V.V., Uvarova I.V., Ragulya A.V. Physicochemical kinetics in nanostructure systems. - Kyiv: Akademperiodika. - 2001, 179 p.

[4] Kazakov N.F. Diffusion wielding of materials. - M.: Machinostroeniye. - 1976, 312 p.

[5] Ustinov A.I., Matvienko A.Y., Poilshuk S.S., Shishkin A.E. Investigation of phase transformation and inelastic deformation in conditions of continuous heating of $\mathrm{Al} / \mathrm{Cu}$ multilayer foil. - Automatic wielding. - 2009. - \#10 - 29-34 p.

[6] GOST 12766.1-90. International standard. High-precision alloy wire with high electrical resistance. Technical conditions. - M., IPK, Standards publishing house, 2003.

[7] Falchenko Y.V., Ustinov A.I., Petrushinets L.V., Melnichenko T.V., Fedorchuk V.E., Yatsenko V.A. - Utility model patent, \#113424 Ukraine, MPK V23K 20/14. Device for diffusion wielding of three-layer honeycombs panels. 2017.

[8] Falchenko Y.V., Petrushintsev L.V., Husarova I.O., Potapov O.M. - Application for a patent \#201701746 - 23.02.2017 Honeycomb filler solid structure and method for honeycomb panel manufacturing. 